\title{
AS BANCAS DE HETEROIDENTIFICAÇÃO RACIAL: APONTAMENTOS A PARTIR DA EXPERIÊNCIA DA UFMG
}

\author{
Alexandre Francisco Braga ${ }^{1}$
}

\begin{abstract}
RESUMO
Desde que as políticas de ações afirmativas foram implantadas nos processos seletivos das universidades públicas brasileiras, incontáveis números de fraudes nas inscrições de autodeclaração racial vieram à tona, muitas vezes em denúncias feitas pelos próprios jovens negros ingressantes nestes processos. Tais desvios de finalidade levaram a instalação de bancas auxiliares de averiguação étnica, as Bancas de Heteroidentificação Racial. Recentemente, decisões e acórdãos legitimaram estas bancas de confirmação étnica e racial como fundamentais aos certames, sejam na Administração Pública seja na Educação Básica e Superior, no duplo sentido de coibir as fraudes e de endereçar as ações afirmativas para quem, justamente, delas necessitam. Este artigo objetiva tracejar alguns apontamentos do uso do expediente das Bancas de Heteroidentificação no Sistema de Seleção Unificada (SISU) da Universidade Federal de Minas Gerais (UFMG), no primeiro semestre de 2019, no qual apontamos, ainda, impasses e disputas exteriores à comunidade acadêmica nos usos do neologismo pardo nas entrevistas dos candidatos e candidatas com recorte na bibliografia do setor jurídico-político e consulta ao Edital do SISU UFMG/2020, cuja hipótese nos permite, a partir de uma breve apresentação histórica da educação, inferir que além de indispensáveis aos processos de seleção, as bancas de confirmação étnica atuam, ainda, de forma a disciplinar e dar maior transparência nos processos seletivos em que o quesito raça/cor é utilizado como categoria de desempate e de promoção de direitos de equidade.
\end{abstract}

PALAVRAS-CHAVE: Bancas de Heteroidentificação. Cotas. Movimento Negro.

\section{RACIAL HETEROIDENTIFICATION STALLS: NOTES FROM THE UFMG EXPERIENCE}

\begin{abstract}
Since the affirmative action policies were implemented in the selection processes of Brazilian public universities, countless numbers of frauds in the registration of racial self-declaration have surfaced, many times in denunciations made by processes. Such deviations of purpose led to the installation of auxiliary stalls of ethnic investigation, the Stands of Racial Heteroidentification. Recently, decisions and ruling shave legitimated these ethnic and racial confirmation stands as fundamental to the contests, whether in the Public Administration or in Basic and Higher Education, in the dual sense of curbing fraud and addressing affirmative actions to those who precisely need them. This article aims to outline some notes on the use of the Heteroidentification Database in the Unified Selection System (SISU) of the Federal University of Minas Gerais (UFMG), in the first semester of 2019, in which we also point out impasses and disputes outside the academic community in the uses of brown neologism in the interviews of candidates and candidates with cut in the bibliography of the legal-political sector and consultation of the SISU UFMG/2020, whose hypothesis, from a brief historical presentation of education, allow sus to infer that in addition to being indispensable to selection
\end{abstract}

\footnotetext{
${ }^{1}$ Alexandre Francisco Braga foi membro titular do Conselho Nacional de Promoção da Igualdade Racial (20132015), compõe a Comissão de Ações Afirmativas e Inclusão da UFMG e é graduando em Ciências do Estado na Faculdade de Direito da UFMG. Email: bragafilosofia@yahoo.com.br.
} 
processes, ethnic confirmation stands also act in such a way as to discipline and provide greater transparency in selection processes where race/color is used as a category for tiebreaking and promoting equity rights.

KEYWORDS: Heteroidentification stalls. Quotas. Black Movement.

\title{
LAS BASES DE HETEROIDENTIFICACIÓN RACIAL: APUNTES DA EXPERIENCIA DA UFMG
}

\begin{abstract}
RESUMEN
Mientras las políticas y acciones afirmativas fueron desplegados en los procesos de selección de las universidades publicas brasileñas, innumerables fraudes en las inscripciones de declaración racial se fue descubierta, muchas veces las denuncias son hechas por los jóvenes negros ingresantes en estos procesos. Ciertos desviaciones en el propósito se hizo necesario la instalación de base auxiliares para la investigación étnica, los Bancos de Heteroidentificación Racial. Recientemente, las decisiones y sentencias legitimaron estos soportes étnicos y raciales de confirmación como fundamentales para las contiendas, sea de Administración Pública o de Educación Básica y Superior en el doble sentido de frenar el fraude y dirigir acciones afirmativas a quienes, precisamente, las necesitan. Este artículo tiene como objetivo esbozar algunos documentos para el uso del archivo de Bases de Heteroidentificación en el Sistema Unificado de Selección (SISU) y en la Universidad Federal de Minas Gerais (UFMG), en el primer semestre de 2019, en el que muestra, todavía, interbloqueos y disputas exterior de la comunidad académica en el uso de pardo como neología en la entrevista de candidatos y candidatas cuya hipótesis permiten inferir, de una breve presentación histórica de la educación, que más alla de indispensables los procesos de selección las bases de confirmación étnica trabajan, todavía, de una manera más disciplinar e mayor transparencia en los procesos selectivos en que el elemento de raza / color se utiliza como desempate y promoción de los derechos de equidad.
\end{abstract}

PALABRAS CLAVE: Bases de Heteroidentificación. Cuotas.Movimiento Negro.

\section{INTRODUÇÃO}

A massa de negros escravizada que aportou no Brasil a partir de 1539 era, em sua quase totalidade, analfabeta, pois tinha matriz linguística Banto, Ewe-Fon, Iorubá. Portanto, a escravaria, apesar de não ser bilíngue, era detentora de outros processos culturais, idiomáticos e relacionais bem diferentes daquela de seus opressores - os portugueses e os espanhóis. Pessoa de Castro (1990) aponta que as diferenças linguísticas não impediram uma atuação socializadora na sociedade colonial, uma vez que negros ladinos empregando rudimentos da língua portuguesa contribuíram para disseminar esse idioma aos seus pares. Da mesma maneira, Silva Neto (1963, p. 82) registra que foi publicada, em Lisboa, a gramática da língua Banto A arte da língua de Angola, escrita pelo padre Pedro Dias, em 1697, com o objetivo de facilitar o trabalho dos jesuítas da Bahia na doutrinação dos escravizados de origem angolana de Salvador. No ethos da sociedade colonial-imperial do Brasil ser escravizado era ser, igualmente, excluído, principalmente do espaço escolar. Isto é, ser um não cidadão. Nesta 
perspectiva, falar de educação de escravizados e ex-escravizados é falar, necessariamente, da trajetória de exclusão, de fomento de desigualdades e de opção política deliberada pela manutenção da subtração da cidadania negra (SILVA NETO (1963) citado por CASTRO (2019, p.1).

Dessa forma, o silenciamento da historiografia educacional vem sendo rompido com a abordagem de novos estudos e pesquisas sérias que ajudam a dar a dimensão do fosso do problema e da imensa distância que separa brancos e negros no processo educativo do País, formal e informalmente. E da gigantesca maldade orquestrada por amplos setores da sociedade escravocrata e colonial contra os cativos que aqui chegaram e permaneceram, e cujas consequências nefastas ainda são sentidas no pós-abolição (1988). Principalmente porque

a legislação proibia a escolarização de crianças escravas e não de crianças negras livres. Aos negros libertos não havia impedimento legal em frequentar a escola, mas tinham de provar ser livres. No entanto, havia a negação das autoridades à educação de cativos libertos, como por exemplo o de uma viúva parda, em Mariana/MG [...] (BASTOS (2016.p. 4).

Ou como funcionavam as dificílimas regras para as escolas destinadas à instrução como o foi o Decreto $n^{\circ}$ 1331-A de 1854 que sancionou o Regulamento da Instrução Primária e Secundária do Município da Corte, que, na prática, quase que inviabilizava as iniciativas populares e autônomas para eliminar o analfabetismo da população e da dos "meninos de cor ${ }^{2}$ ".

Havia uma relação pedagógica, que se dá lentamente, e motivada por fortes convicções econômicas para inserir o escravizado como não cidadão, mas cuja figura era essencial para a manutenção financeira do sistema escravista e da sobrevivência das gentes imperiais. Neste aspecto, foi uma necessidade política formar mão de obra servil para prestar assistência e realizar tarefas das mais abomináveis e das mais sofisticadas para satisfazer os membros do senhorio, da Casa-Grande, numa relação que Menezes (2007, p. 148) denominou de "laços extraeconômicos de submissão". Esta relação pedagógica estava circunscrita em socializar os escravizados e escravizadas para realizarem bem funções trabalhistas, domésticas, no campo e na cidade. Em suma: "para tornar-se cidadão, faltava ao ex-escravizado o "batismo" do ensino - garantia da sua entrada na civilização letrada, escrita, ocidental, como também passaporte para a brasilidade" (MENEZES, 2007, p.151). Nesta medida, esta estratégia pedagógica era:

A formação do escravo, por outro lado, era uma pedagogia em que estava envolvida a inculcação da sua condição de escravo, do papel que devia desempenhar e dos seus deveres. Esta inculcação se dava tanto através da catequese, da religião católica, como através de todo um sistema de punições,

${ }^{2}$ Pretextato dos Passos e Silva foi pioneiro em ações afirmativas no país entre 1853 e 1873. Cf.: Silva (2002). 
de castigos, que demarcavam perfeitamente o seu "lugar" de escravo (MENEZES, 2007, p. 153).

Com isso, vale ressaltar que nesta observação feita por Menezes acima descrita, cabe registrar que alguns africanos já vieram prontos para a labuta servil. Karash (2000) chama a atenção, nesse sentido, de certo grupo de africanos aportados no Rio de Janeiro que tinham capacidade de ler, falar e escrever em português. Outra hipótese é o uso da habilidade e da esperteza oferecidas pelos momentos que foram assinalados quando em algumas circunstâncias

[...] que teriam oportunizado o acesso às letras pelos escravizados. Uma possibilidade que se apresentava no cotidiano de alguns cativos estava relacionada à tarefa de acompanharem as crianças à escola (considerada uma atividade corriqueira para as mucamas, por exemplo). Ocasião em que teriam a chance de aprenderem ouvindo as lições destinadas aos filhos dos senhores. (KARASH (2000) citada por BASTOS (2016, p. 5).

Outra intenção dos senhores de engenho e proprietários de escravarias era ensinar os filhos de escravizados como tentativa de receber melhor renda, na hora da venda do escravizado e, também, encaminhar os escravizados de sexo masculino para educandários para aprenderem ofícios específicos (BASTOS, 2016, p. 7). Por meio dessa didática, conforme Mattoso (1982) e Bastos (2016), ao cativo era apresentado o universo linguístico, com um aprendizado das línguas e falares locais. Ao chegar a certo nível de compreensão destas virtudes, o negroescravizado era promovido à categoria de negro ladino (MAESTRI, 2004, p. 200).

Contudo, as parcas e ricas experiências educacionais alcunhadas por Maestri (2004) de "pedagogia da escravidão," da época não livraram o Brasil do trauma da exclusão social e do iletramento amplo, geral e irrestrito, na medida em que o acesso à instrução pública e de maior prestígio ficou franqueada para a população endinheirada e de posses (escravizados, terras, renda e convívio social na Corte). Num panorama que associava a necropolítica ${ }^{3}$ dos senhores de engenho ao regulamento das castas imperiais que impediam a mobilidade e a diminuição das desigualdades sociais oriundas desse período. Inclusive, com o emprego de uma legislação extremamente perversa para os processos de superação social e que, pasmem, favorecia aos grupos europeus estimulados pelo governo a partir de 1850, já prevendo a substituição da mãode-obra escravizada e com clara estratégia de evitar um empoderamento negro-escravizado inspirado na Revolução Haitiana (1971-1804).

\footnotetext{
${ }^{3}$ Poder e capacidade de ditar quem pode viver e quem deve morrer na sociedade moderna. Cf::Mbembe (2016).
} 
Corroborando com as análises desta pedagogia da escravidão, Angela Davis (2018), em A Liberdade é uma Luta Constante, enfatiza que o "[...] uso da violência estatal contra a população negra, contra as minorias étnicas, tem origem em uma época muito anterior ao movimento dos direitos civis - na colonização e na escravidão" e que, o que é preciso ser ressaltado na promoção das políticas educacionais, [...] "tal movimento não dirimiu práticas originárias da escravidão.” (DAVIS, 2018, p. 31).

Portanto, as interdições à população negra, ex-escravizada, crioula, parda e recémliberta no processo societário, foram permeadas pela opção institucional de somente conferir cidadania aos não de cor, de matriz imperial e com posses materiais esteticamente identificáveis no seio da sociedade colonial. Ao longo da trajetória de consolidação das formações sociais no Brasil este racismo estrutural será a marca de todo este processo. Ainda que houvessem tratativas para diminuir o impacto da escravidão e da segregação nesta trama e das iniciativas para letrar e educar os escravizados que iam aportando em terras brasileiras, digo, "mares", para melhorar o desempenho das unidades produtivas dos senhores de engenho, como a formação de solidariedade nas senzalas, como a catequese para aportuguesar os incautos e demais ações voluntárias e autogestionadas dos próprios negros, o grande traço da sociabilidade nacional vai ser o impedimento legal à fruição da população negra aos gozos sociais. Duas justificativas para este apontamento estão baseadas na legislação restritiva de direitos que figurou no País até bem pouco tempo atrás. Uma delas, visando ao embranquecimento demográfico, favoreceu a vinda para o Brasil de escores de origem europeia e asiática, notadamente oriundos da Itália, Polônia, Alemanha, Suíça, Espanha, Japão, China, entre outros grupos étnicos. Por meio desta engenharia social, pretendia-se, além de "branquiar" a população, fornecer, de forma curta e rápida, trabalhadores e trabalhadoras para as funções que anteriormente eram exercidas de forma compulsória pelos escravizados, porém, pagos à soldo e recebendo incentivos fiscais, assistenciais e diplomáticos que os ex-escravizados não tiveram.

Este fluxo migratório foi iniciado por fazendeiros logo após a aprovação da Lei Euzébio de Queiróz ${ }^{4}$ (1812-1868), já planejando a substituição de mão de obra escravizada pela assalariada. Santos (2002) informa que esta nova tática foi aprovada durante a realização do Congresso Agrícola, realizado no Rio de Janeiro por cafeicultores preocupados com as colheitas das lavouras do setor. Com o transcorrer dos tempos e das demandas causadas pela onda abolicionista, foi tornando-se uma prática oficial da política pública imigratória do Brasil.

\footnotetext{
${ }^{4}$ Autor da lei que oficializou a proibição do tráfico negreiro.
} 
Em Decreto de $n^{\circ} 528$, de junho de 1890, ainda no auge da recém-lançada abolição da escravatura, o marechal e primeiro presidente da nossa era republicana, Marechal Deodoro da Fonseca (1827-1892), promulgou uma série de restrições para entrada de africanos em terras brasileiras. Entre elas, “a policia dos portos da Republica impedirá o desembarque de taes individuos, bem como dos mendigos e indigentes" (BRASIL, 1890), cujas condições e autorizações deveriam ser feitas pelo Congresso Nacional; e as despesas de viagem e moradia, com gratuidade total ou parcial, ficavam por conta do erário, caso os imigrantes estivessem dentro perfil desejado pela elite nacional, como varões entre os 18 e 50 anos vocacionados para o trabalho na área agrícola (BRASIL, 1890). De acordo com o artigo 121, $\S 6^{\circ}$, da Constituição de 1934, o Brasil adotava uma cota-limite de 2\% para entrada de imigrantes nacionais no País:

A entrada de immigrantes no territorio nacional soffrerá as restricções necessarias á garantia da integração ethnica e capacidade physica e civil do immigrante, não podendo, porém, a corrente immigratoria de cada paiz exceder, annualmente, o limite de dois por cento sobre o numero total dos respectivos nacionaes fixados no Brasil durante os ultimos cincoenta annos. (BRASIL, 1934).

Para cumprir estas deliberações e acordos políticos com o setor agropecuário brasileiro, na tentativa de atrair trabalhadores e trabalhadoras imigrantes de pele branca, além destes dispositivos constitucionais e legais, foram criados diversos subsídios para facilitar a entrada e a permanência dos novos brasileiros. Primeiramente, por São Paulo, ainda no ano 1847; e em 1886 é criada a Sociedade Promotora de Imigração, ${ }^{5}$ que doava passagens grátis para os interessados em vir para o Brasil, e foi a responsável por boa parte da entrada de imigrantes até 1930, sendo que seu braço hospitaleiro, a Hospedaria dos Imigrantes (fundada em 1887), atuou até 1978, conforme Lanza e Lamounier (2015.p.95).

\section{CONTEXTO DAS AÇÕES AFIRMATIVAS}

Em consequência das proibições do acesso dos negros (ex-escravizados, pardos, pobres, forros) às políticas educacionais e ao convívio social com a população branca, foi gerado os primeiros processos de desigualdade social que marcaram e, ainda marcam, a sociabilidade do capital no Brasil (CHASIN,[s.d.]). Desigualdade social, gerada e orquestrada pelas posições políticas das elites visando à manutenção de um sistema oficial, ao mesmo tempo, economicamente exproprietário, atrasado e segregacionista, cujo apartheid mantinha separados

\footnotetext{
${ }^{5}$ Foi substituída pela Secretaria de Agricultura, Comércio e Obras de São Paulo em 1895.
} 
e criou graus diferentes de cidadania, como vimos nos já citados decretos $n^{\circ} 1.331$ de 1854 , durante a Monarquia, e o de n 528 de 1890, da República. O Regulamento da Instrução Primária e Secundária do Município da Corte era uma clara ação das agências com objetivo de impedir que escravizados, forros e livres, ou seja, a massa da população negra da época, fossem à escola.

Isto posto, é correto o apelo político militante para criarem ações afirmativas exclusivas para negros e negras no Brasil na medida em que, na verdade, tais ações já eram praticadas para valorizar estoques euroasiáticos em terras nacionais ou para servirem de estímulo para que imigrantes aportassem em nosso solo motivados por regalias sociais e financeiras patrocinadas pelo erário e moldadas para atender aos interesses dos fazendeiros paulistas e cariocas, como é o caso da Sociedade Promotora de Imigração e da promulgação da Lei do Boi ${ }^{6}$, cuja cota era de $50 \%$ em estabelecimentos de ensinos agrícolas, no nível médio e superior, nos cursos de Agricultura e Veterinária para os filhos de fazendeiros.

Dentro desta lógica, era natural a reivindicação negra para a extensão das políticas de ações afirmativas para o conjunto da população negra, tendo em vista que vários outros grupos populacionais já vinham gozando desta prerrogativa; e, justamente, os grandes merecedores das cotas raciais que tinham vivenciado episódios de "holocausto" não tiveram acesso nem a estas ações nem a qualquer outro dispositivo de assistência social da parte do Estado ou da Igreja Católica. O exemplo do negro Pretextato dos Passos e Silva, ao empreender a primeira escola de formação cívica para ex-escravizados e livres no Rio de Janeiro com autorização de funcionamento dada pelo ministro da Justiça Euzébio de Queirós (1812-1832) configura ação pioneira das políticas afirmativas negras no País (SILVA, 2002). No entanto, a atitude de Pretextato Silva nem de longe se compara aos incalculáveis instrumentos e regalias disponíveis para a população branca imigrante e estrangeira para morar no Brasil e, também, as ações voltadas aos negros foram insuficientes para pelo menos diminuir o racismo institucional vigente. Por outro lado, as políticas de ações afirmativas brancas impulsionaram um ethos que ainda hoje mantêm privilégios de branquitude.

Contrários a este status quo que foi naturalizado, a Frente Negra Brasileira (FNB) (1931-1937) retoma a luta para denunciar a segregação racial contra os negros e os modos diferentes como eram tratados os brancos e as brancas nas políticas públicas brasileiras, uma

${ }^{6} \mathrm{~A}$ Lei do Boi criou cotas de 50\% nos estabelecimentos de ensino médio agrícola e nas escolas superiores de Agricultura e Veterinária para filhos de fazendeiros e funcionou até 1985. 
vez que a abolição da escravatura foi uma vitória popular material, mas não formal. De acordo com Domingues (2008, p. 350), "havia, segundo dados do Anuário do Ensino de 1917, 565 escolas particulares, das quais 464 eram brasileiras e 101 das colônias de imigrantes (italianas, alemãs, norte-americanas, portuguesas, suíças, francesas e inglesas”. Portanto, era contra esta exclusão educacional que a Frente Negra Brasileira (FNB) criou seu departamento de Instrução e Cultura, no qual pregava: "eduquemos mais e mais os nossos filhos, dando-lhe uma educação e uma instrução de acordo com as suas aspirações." (A VOZ DA RAÇA, 1933, p. 4).

E a gente negra especialmente. Porque é ela, entre todos os mais brasileiros, a mais descuidada, a mais fútil ao gastar, a mais imprevidente nos dispor dos bens que Deus permite que, com boa saude [sic], ela possa adquirir. (A VOZ DA RAÇA, 1933, p. 1).

Dispondo desta análise sócio-política, a FNB defendeu em sua linha educacional um projeto político-pedagógico de valorização do pertencimento étnico, como observa Araújo (2013, p.41):

Ao problematizar o projeto educacional da Frente Negra Brasileira - sua organização e funcionamento, seu corpo docente e sua relação com as outras escolas do período - identifiquei que a escola primária foi criada a partir do anseio daqueles militantes negros em dar aplicabilidade prática às ideologias acerca do saber escolarizado como instrumento de ingresso e mobilidade social no mundo moderno e industrial. Outrossim, também surgiu como alternativa às dificuldades de acesso às escolas oficiais e pela necessidade de instituir um projeto educacional com características culturais especificas, a exemplo das escolas dos imigrantes que proliferaram no período. Em suma, os negros desejavam garantir um espaço social negro, além da possibilidade de receberem uma educação que estivesse "livre da coação do racismo", por meio de práticas pedagógicas de valorização do pertencimento étnico-racial.

A partir desta abordagem da elevação moral, intelectual, artística e técnica profissional dos negros, a FNB buscava criar cooperativas econômicas e escolas técnicas de ciências e artes com inspiração integralista (A VOZ DA RAÇA, 1933).

Uni-vos! Uni-vos negros! Uni-vos todos. Deus está conosco! Uni-vos, pela elevação moral, intelectual e econômica da Raça! Pela Dignidade da Mulher Negra! Pela dignidade e progresso do trabalhador negro! Pela afirmação política da Gente Brasileira na Constituinte quando vier e depois da Constituinte quando vier! Pelo Brasil de nossos Avós! (MANIFESTO À GENTE NEGRA BRASILEIRA, 1931, [s.p]).

Em meados de 2001, as pautas educacionais ganham maior fôlego, com ressonância internacional e maior adesão dos programas eleitorais partidários. Diferentemente das fases anteriores, em que as propostas pedagógicas eram destinadas quase que exclusivamente às populações brancas de matrizes europeia e asiática e as ações afirmativas focavam um público restrito de filhos e filhas de fazendeiros e imigrantes com interdições aos negros, a partir deste 
Braga; A. F.

recorte temporal as políticas públicas de ações afirmativas, atendendo a apelos do Movimento Negro, que vinha durante mais de 70 anos reivindicando a viragem histórica pela reparação dos estragos societários deixados pela escravidão, agora tais ações ganham marcos legais institucionais nas agências, dentro e fora do Brasil. Contribui, sobremaneira, a aprovação da Declaração e do Programa de Ação de Durban, aprovados durante a realização da III Conferência Mundial contra o Racismo, Discriminação Racial, Xenofobia e Intolerância Correlata, realizada em 31 de agosto de 2001, em Durban, na África do Sul, sob os auspícios da Organização das Nações Unidas (ONU), na qual

[...] solicita que os Estados, apoiados pela cooperação internacional, considerem positivamente a concentração de investimentos adicionais nos serviços de saúde, educação, saúde pública, energia elétrica, água potável e controle ambiental, bem como outras iniciativas de ações afirmativas ou de ações positivas, principalmente, nas comunidades de origem africana. (DECLARAÇÃO E DO PROGRAMA DE AÇÃO DE DURBAN, 2001).

Por meio destas ações, denominadas pela ONU de Ações Afirmativas ou Ações Positivas, diversos países adotaram, oficialmente, de forma parcial ou total, algum nível de ação afirmativa, entre eles Brasil, Colômbia, Canadá, Cuba, Índia, Israel, Equador, entre outros. E a legislação brasileira considerou as medidas recomendadas pela ONU como constitucionais para seleção de candidatos e candidatas nas universidades públicas aos processos seletivos na modalidade de cotas étnico-raciais (ADPF $\left.\mathrm{n}^{\circ} 186,2009\right)$. Haja vista que a Universidade do Estado do Rio de Janeiro, a Universidade Estadual do Norte Fluminense Darcy Ribeiro, a Universidade do Estado da Bahia, a precursora, e a Universidade Brasília já vinham adotando mecanismos específicos para selecionar seu corpo discente nesta modalidade. Com a aprovação da Lei $\mathrm{n}^{\mathrm{o}}$ 12.711, de agosto de 2012, o ingresso nas universidades públicas e instituições federais de ensino técnico de nível médio passou a ter uma reserva de vagas como uma grande agenda histórica de inclusão educativa no País.

\section{A EXPERIÊNCIA DAS BANCAS ÉTNICAS DA UFMG}

Sair da senzala e, consequentemente, assumir a negritude em suas várias tonalidades, com autoestima elevada e orgulhoso sentimento de pertencimento à raça negra. Além dessas intenções, a adoção de cotas raciais nos processos seletivos nas políticas públicas educacionais 
e de gestão governamentais impactam, ainda, historicamente, na vida da sociedade brasileira, na medida em que diversas gerações serão oportunizadas pelas aplicações específicas para os alvos a que se destinam. Todavia, o aspecto humanitário das cotas raciais para negros e negras, bem como o apreço jurídico da mais alta Corte brasileira, que considerou instrumento constitucional indispensável e necessário para amparar populações expurgadas do gozo social, o explosivo número de denúncias de fraudes em partes do processo seletivo na modalidade cor/etnia resultou na indispensável aplicação de instrumentos complementares da autodeclaração étnico produzidas pelos candidatos e candidatas - as Bancas de Heteroidentificação (BHD).

Ressalta-se que as Bancas de Heteroidentificação produzem pareceres a partir do olhar fenotípico de terceiros para efetivar a continuidade do processo seletivo, seja em ingresso na universidade/faculdade/escola ou concurso público. Nesse sentido, não deslegitima ou descredencia a autodeclaração, mas enfatiza, para os efeitos, jurídicos e políticos, perquiridos de destinação das ações afirmativas qual ou quais daquelas (es) candidatas (os) apresenta uma leitura pública de pertencimento afro-brasileiro, negro (a), ressalvando que, em que pensem a deliciosa e a rica mistura racial do País e a grande miscigenação nacional, as pessoas pretas são facilmente identificáveis nas estatísticas das vítimas da discriminação racial, da violência policial e nas pesquisas sobre dados da desigualdade social em diferentes âmbitos da vida brasileira, principalmente na busca por emprego decente no mundo do trabalho.

Dessa forma, se não temos dúvidas de quem é negro (a) no Brasil para efeitos de identificar as vítimas do racismo e de convivência societária negativa desde a época da escravidão, não haverá, muito menos dúvidas, para "selecionar" tais candidatos negros (as) nestes certames, mesmo tendo graus variáveis de subjetividade ${ }^{7}$. Porque a BHD não diz quem é negro e quem não é, ela, tão somente, perfila para as autoridades, a partir dos requisitos do Edital, quem está apto para provimento, dentro das características fenotípicas (cor da pele, traços físicos, cabelo) apresentando, presencialmente, perante a banca avaliadora, tais amostragens. Isto porque de acordo com Nunes (2018, p. 29): “as comissões não fazem um julgamento de corpos, mas instauram um processo político de acolhimento e recepção aos

\footnotetext{
${ }^{7}$ Como não há uma validade científica para determinar quem é negro, do ponto de vista genético, usamos o interesse político com o objetivo de facilitar a inclusão e extirpar as desigualdades que violam os direitos das pessoas de pele preta, de ascendência e descendência afro-brasileira.
} 
corpos esquecidos, interditados e normatizados pelo racismo". E a $\mathrm{BHD}^{8}$ tem responsabilidade procedimental para averiguar a raça social do indivíduo!

Na Universidade Federal de Minas Gerais $\left(\mathrm{UFMG}^{9}\right)$, após um intenso movimento realizado pelo Movimento Negro da UFMG através da produção de um dossiê com 61 suspeitas de fraudes ${ }^{10}$ na autodeclaração étnica e após a onda de repercussão negativa na mídia e na sociedade mineira, desde 2019 os neófitos aos cursos de graduação, ensino médio técnico e habilidades específicas aprovados no Sistema de Seleção Unificada (SISU)/Vestibular do Colégio Técnico que se autodeclararam negros (pretos ou pardos) devem apresentar, no momento da matrícula presencial, a Carta Consubstanciada e passar, obrigatoriamente, pelo crivo da Comissão Complementar à Autodeclaração, composta por membros da comunidade acadêmica, oriundos dos três setores - servidores técnico-administrativos, docentes e discentes da graduação ou pós-graduação ambos com notório saber em temas afro-indígenas (UNIVERSIDADE FEDERAL DE MINAS GERAIS, 2019, p. 2).

Nesse diapasão, a UFMG (2019, p.6), informou no Edital do SISU/2019 que "além de observação de fenótipo, mecanismos adicionais poderão ser utilizados tais como: entrevistas; aplicação de questionários com múltiplas questões sobre cor/raça," e realizar acordos e convênios com instituições autárquicas e entidades públicas com vistas a acessar bancos de dados públicos para avaliar as veracidades das informações prestadas pelos candidatos e candidatas inscritos em seus certames, como, por exemplo, consulta ao Cadastro Único de Programas Sociais (CADúnico) seja nos campi de Belo Horizonte ou de Montes Claros. Isto é, a universidade dispõe de diversas formas de comprovar as veracidades das informações prestadas pelos pretendentes.

Desse ponto de vista, o ex-Pró-Reitor de Assuntos Estudantis da UFMG, professor Rodrigo Ednilson de Jesus, acrescenta que a Carta Consubstanciada e a BHD são dois instrumentos que

[...] aumentam os custos de uma autodeclaração falsa, contribuem para que o candidato reflita sobre o modo como é visto pela sociedade e auxiliam a Universidade no aprimoramento dos seus métodos de acompanhamento dessa política. (ARAÚJO, 2019, p.1).

\footnotetext{
${ }^{8}$ Para efeitos jurídicos e políticos, a variação de Comissão ou Banca de Avaliação Étnico-Racial, Comissão de Verificação COR/Etnia ou Comissão Complementar de Heteroidentificação tem a mesma significância.

${ }^{9} \mathrm{O}$ conjunto de informações sobre o processo seletivo na UFMG estão disponíveis em https://www.ufmg.br/sisu/wp-content/uploads/2019/12/Edital-Sisu-UFMG-2020.pdf.

${ }^{10}$ Algumas suspeitas de fraudes geraram 34 Processos Administrativos que aguardam perecer final da instituição. Cf.: https://www.em.com.br/app/noticia/gerais/2018/05/18/interna_gerais,959667/escandalo-de-cotas-na-ufmg34-processados-28-e-suspeitos-por-fraude.shtml.
} 
Esse ato processual sigiloso consiste em uma comissão de cinco membros, cada um com seu laptop, com senha individual; e durante o período de análise das candidaturas PPI (Pretos, Pardos, Indígenas) ficam incomunicáveis entre si, conforme modelo de banca de verificação étnica enviado por meio de ofícios encaminhados pela Unegro (União de Negras e Negros Pela Igualdade) às Instituições Federais de Ensino Superior de Minas Gerais, como a Universidade Federal de Lavras, Universidade Federal de Juiz de Fora, Universidade Federal de Viçosa, Universidade Federal de Ouro Preto e a própria UFMG, de maneira absolutamente respeitosa com os candidatos e candidatas (UNIÃO DE NEGRAS E NEGROS PELA IGUALDADE, 2017).

Tabela 1 - Bancas de Heteroidentificação da UFMG 2019 reserva de vagas para pessoas negras

\begin{tabular}{cccc}
\hline $\mathbf{N}^{\mathbf{0}}$ Inscritos & Ausentes & Indeferidos & Confirmados \\
$\mathbf{1 . 8 5 0}$ & $\mathbf{7 5 3}$ & $\mathbf{5 2 3}$ & $\mathbf{5 7 2}$ \\
\hline FONTE: & Elaboração própria a partir de dados da Comissão Permanente de Ações Afirmativas e Inclusão da \\
UFMG $^{11}$.
\end{tabular}

Conforme podemos inferir na Tabela 1, a ausência de 753 candidatos e candidatos perante a Banca de Heteroidentificação Racial da UFMG no $2^{\circ}$ semestre de 2019 é percebida por motivações variadas, não sendo possível tracejar uma única causa para tal desistência e cuja ausência física configura eliminação destes candidatos e candidatas do processo seletivo na modalidade de reserva de vagas para pessoas negras. Outro aspecto a considerar é que a reprovação de $69 \%$ dos aspirantes, conjunto compreendido entre os ausentes e os indeferidos, revela uma postura ortodoxa da UFMG em defesa do merecimento das cotas raciais, com uma alta taxa de reprovação e uma baixa judicialização de seu SISU 2019, na medida em que somente 67 pretendentes acionaram a Justiça Comum contra os resultados proclamados pela Universidade.

Neste certame, participaram 50 avaliadores - servidores (docentes e técnicoadministrativos) e estudantes da graduação e pós-graduação, membros da Comunidade Universitária -, no qual cada banca foi composta por cinco pessoas de diferentes etnias, com percurso temático e histórico de pesquisa afro-indígena e trajetória de defesa dos direitos

\footnotetext{
${ }^{11}$ Relatório apresentado pela professora Shirley Aparecida de Miranda "Procedimento de Heteroidentificação: breve relatório do Registro Acadêmico 2019/2".
} 
humanos. Além do que, obrigatoriamente, todos e todas participaram, ainda, de seminário de formação e capacitação de 6 horas, visando atualizar conhecimentos referentes ao universo jovem estudantil, ao surgimento de problematizações relacionadas aos processos seletivos no âmbito da Administração Pública com recorte racial e das agendas de lutas pela promoção da igualdade racial e combate às diversas facetas do racismo institucional e estrutural, dentro e fora das universidades brasileiras.

\section{A EMINÊNCIA PARDA NOS PROCESSOS SELETIVOS RACIAIS}

À noite, todos os gatos são pardos. Karl Marx

Obviamente que apesar do sucesso das políticas de inclusão social para negros e indígenas usando como mecanismos as cotas raciais no setor da educação e nos ingressos nas carreiras dos serviços públicos, não só os problemas das fraudes trouxeram decisões delicadas a que seus realizadores tiveram que se submeter para garantir a efetividade das políticas afirmativas, mas ainda, a própria concepção do elemento pardo elevou a temperatura do tensionamento nestes processos seletivos. Isto porque, ao enfatizar a absoluta soberania da autodeclaração como categoria de alteridade e de afirmação do direito à inviolabilidade e da presunção da inocência, restou um processo complexo quando não há o complemento com demais instrumentos de averiguação étnica, e em certos aspectos impossível, dizer-se fraude nesta declaração que tem fé pública uma vez que a fraude no certame com modalidade de cota racial não se dá, exclusivamente, no conteúdo do que está expresso e escrito pelo pretendente, mas no comportamento mostrado perante a banca/comunidade realizadora da seleção. Recentemente, foram percebidas o crescimento de candidaturas pardas que reivindicam acesso às ações afirmativas cujo pertencimento, à luz do convívio social, se assemelham ao padrão de branquitude, e nessa teia relacional, não apresentam os mesmos sofrimentos raciais que sofrem as populações pretas retintas, e que, portanto, não precisam das políticas afirmativas.

Assim dito, não basta autoproclamar-se pardo para ter acesso direto e automático ao concurso via cotas raciais, pois nem todos os autoproclamados negros apresentam resultados de segregação iguais; alguns pardos apresentam relações bivariadas diferentes. Isso ocorre porque, conforme, Telles e Lim (1998), a discriminação depende mais de como as pessoas são classificadas pelos outros do que da maneira como elas mesmas se enxergam.

Trazemos à baila a questão da morenidade, porque, vencidos os percursos da confirmação da negritude nas seleções por meio das cotas identitárias, restaram dúvidas quanto 
ao direito do pardo em se beneficiar do instrumento específico, ainda que este marcador esteja agregado na categoria de não brancos, os negros. Ainda que constem em Leis soberanas e no aparato jurídico-normativo e, principalmente, sejam descendentes da miscigenação brasileira, cabocla ou mulata (este termo entrou em desuso por causa de seu viés pejorativo), na medida em que há um grupo de pardos mais próximos de características fenotípicas brancas (cor da pele, pelagem e demais traços físicos) que não são atingidos pelo racismo e nem configuram dinâmicas de desigualdades raciais no mundo do trabalho, no transporte público, nas abordagens policiais e nem nas projeções das mídias. Alguns grupos de pardos não carecem, assim, acessar políticas públicas destinadas a reparar o trauma da segregação racial os quais não sofrem.

Como os brancos são maioria entre as pessoas de nível socioeconômico mais elevado e no Brasil há uma forte endogamia de classe, os não brancos que atingem mobilidade social não têm muitas opções que não se casar com brancos. Entre eles, os pardos seriam os mais propensos a fazê-lo, uma vez que o fato de serem vistos como estética e culturalmente mais próximos dos brancos aumenta as suas chances de incorporação a uma elite que impõe a branquidade como padrão. (SCHWARTZMAN, 2007, citada por Daflon; CARVALHAES; JÚNIOR, 2017, p.31).

A partir dessa ponderação feita por Daflon, Carvalhaes e Júnior (2017), ao citarem Schwartzman, os pardos esteticamente e culturalmente identificados como brancos serão lidos nas BHD como pessoas brancas mesmo que haja nos Editais garantias que lhes assegurem participar das etapas seletivas na categoria negro (preto/pardo). Tanto porque alguns pardos conseguem mobilidade social ao superarem as amarras discriminatórias que a maioria da população negra de pele retinta não conseguiu e nem consegue romper, quanto porque o trânsito de uma identidade social e racial para outra oferece possibilidade e oportunidades de acordo com o contexto da socialização que o conjunto de pardos possui. Isto é posto assim, porque há uma perspectiva em que as elites tendem a selecionar e a aceitar como seus aqueles com tonalidade de pele idêntica a si, o que Daflon (2017, p.324) observa como uma branquitude adaptativa no Brasil, já que seleciona requisitos físicos e comportamentais para manter intacto o edifício racial brasileiro (DAFLON, 2017.p. 324). Desta forma, o alto índice de reprovação da modalidade racial da UFMG indica uma opção nesta direção, de que nem todo autodeclarado pardo precisa, deve ou carece de usar tal modalidade em eventos de seleção pública. Ainda que conste de jure como membro da categoria negro, o elemento pardo é socialmente lido como pessoa que não passa pelas mesmas agruras e sofre discriminação racial que justifica adoção para si de importantíssima ferramenta de luta contra o racismo! 
Enfim, o elemento pardo nos processos de políticas afirmativas ainda carece de uma fundamentação e um escurecimento do ponto de vista de quais são suas prerrogativas e quais filtros lhes imputam os certames destinados aos negros e negras que são as vítimas do preconceito de marca, portanto, sócioespacial, que justificam uma linha de adoção de ação afirmativa antirracista na qual tais grupos participam. Outrossim, fora destas políticas afirmativas, na sociedade mesma, a própria sociabilidade já os incorporou, positivamente, como membros frutos da miscigenação brasileira.

\section{CONSIDERAÇÕES FINAIS}

Desde o início do ano 2001, o Brasil vem numa trajetória inclusivista histórica que tem moldado as políticas públicas governamentais e que alterou a rota das ações afirmativas que antes eram restritas às populações brancas de matrizes asiáticas e europeias. A partir deste marco temporal, as populações negras e indígenas, e, mais recentemente, pessoas acometidas por deficiências (PcD), quilombolas, pessoas trans, mulheres, refugiados políticos, apátridas e imigrantes foram inseridos neste rol de garantias de direitos, e, oxalá, demais membros das categorias de menos prestígios social e econômico. Hoje, a amostra dos beneficiários das políticas identitárias abrange um leque multifocal e com um raio bem maior daquele imaginado por ativistas do Movimento Negro e legisladores, pois tais políticas não se restringem à educação e tendem a aumentar o espectro de atingimento para consolidar uma rota de solidariedade humana da mais significativa que o País começou a trilhar. Apesar do notório caráter humanitário das ações afirmativas adotas, ainda podem e vão aparecer tensionamentos - ideológicos, políticos e orçamentários -, que podem pôr em debate o real alcance destas ações afirmativas numa nação tão miscigenada como a do Brasil, linda por natureza, abençoada por Deus e profana e sagrada por tradição.

Como vimos ao longo deste texto, o elemento pardo é um desses novos desafios conceituais postos no debate público que a política governamental deverá se debruçar para aprimorar a inclusão social, e é bom que se diga que jamais tivemos a pretensão de abarcar em totalidade ou esgotar um debate racial complexo e apaixonante, cuja abordagem vai precisará de mais escritas e mais pesquisas de qualidade para ir fomentando uma opinião pública que possa pensar a nação brasileira que não deixou de ser violenta devido às novas políticas públicas afirmativas adotas. Mas, que é possível inferir que as cotas raciais vão dar aos sujeitos, não só a categoria de pertencimento de direitos, mas a própria condição de melhorar a luta contra a violência e o racismo no momento em que a educação liberta e emancipa! 
Contudo, superar a problemática das fraudes nos processos seletivos através das bancas de verificação étnico-racial é uma forma de garantir que tais instrumentos sejam realmente destinados a quem precisa. Aí sim!, a trilha societária estará sendo orientada para construir um Brasil alegre, negro, progressista e humanitário.

\section{REFERÊNCIAS}

A VOZ DA RAÇA.23 de outubro de 1933.Disponível em: http://biton.uspnet.usp.br/imprensanegra/index.php/a-voz-da-raca/a-voz-da-raca-23101933/. Acesso em: 22 jun.2019.

ARAÚJO, Ana Rita.Inclusão mais justa: Banca de verificação e comissão complementar à autodeclaração aperfeiçoam política de cotas na UFMG.Boletim. $\mathrm{N}^{\circ} 2047$.Ano 45.18 fev.2019.Disponível em:

https://ufmg.br/comunicacao/publicacoes/boletim/edicao/2047/inclusao-mais-justa. Acesso em:22 jun.2019.

ARAÚJO, Márcia Luiza Pires de.A Escolarização de Crianças Negras Paulistas (19201940).2013.202f.Tese (Doutorado).Faculdade de Educação, Universidade de São Paulo, São Paulo,2013.Disponível em:

file://C:/Users/CAR/Downloads/MARCIA_LUIZA_PIRES_DE_ARAUJO_rev.pdf. Acesso em: 05 jun.2019,

BASTOS. Maria Helena Camara.A Educação dos Escravos e Libertos no Brasil: Vestígios esparsos do domínio do ler, escrever e contar (séculos XVI a XIX).Cadernos da História da Educação.v.15, n.2,p.743-768, 2016.Disponível em:

http://sfbct.unimc.it/it/documentihome/materialinews/dispensa4_bastos.Acesso em: 22 jun. 2019.

BRASIL.[Constituição (1934)].Constituição da República dos Estados Unidos do Brasil de 1934. Rio de Janeiro,16 jul. 1934. Seção 1, p. 1. Disponível em:

https://www2.camara.leg.br/legin/fed/consti/1930-1939/constituicao-1934-16-julho-1934365196-publicacaooriginal-1-pl.html. Acesso em: 22 jun. 2019.

BRASIL.Decreto No 528, de 28 de junho de 1890. Regularisa o serviço da introducção e localisação de immigrantes na Republica dos Estados Unidos do Brazil. Coleção de Leis do Brasil-1890,p.1424,v.1,fasc.V.Disponível em:https://www2.camara.leg.br/legin/fed/decret/1824-1899/decreto-528-28-junho-1890506935-publicacaooriginal-1-pe.html.Acesso em:22 jun.2019.

BRASIL.Decreto N $N^{\circ} 1.331$, de 17 de fevereiro de 1854. Approva o Regulamento para a reforma do ensino primario e secundario do Municipio da Côrte.Coleção de Leis do Brasil1854,p.1424,v.1,fasc.V.Disponível em: https://www2.camara.leg.br/legin/fed/decret/18241899/decreto-1331-a-17-fevereiro-1854-590146-publicacaooriginal-115292pe.html\#: :text=Veja\%20tamb\%C3\%A9m\%3A,DECRETO $\% 20 \mathrm{~N} \% \mathrm{C} 2 \% \mathrm{BA} \% 201.331 \% 2 \mathrm{DA} \% 2 \mathrm{C} \% 20 \mathrm{DE} \% 2017 \% 20 \mathrm{DE} \% 20 \mathrm{FEVEREIRO}$ $\% 20 \mathrm{DE} \% 201854$,secundario $\% 20 \mathrm{do} \% 20$ Municipio $\% 20 \mathrm{da} \% 20 \mathrm{C} \% \mathrm{C} 3 \%$ B 4 rte.\&text $=$ Palacio $\%$ 20do $\% 20$ Rio $\% 20 \mathrm{de} \% 20 J a n e i r o, d a \% 20$ Independencia $\% 20 \mathrm{e} \% 20 \mathrm{do} \% 20 \mathrm{Imperio}$.Acesso em:03 jul. 2020. 
BRASIL.Lei $\mathrm{n}^{\circ}$ 12.711, de 29 de agosto de 2012.Dispõe sobre o ingresso nas universidades federais e nas instituições federais de ensino técnico de nível médio e dá outras providências.Diário Oficial da União.30 ago.2012.Disponível em: http://www.planalto.gov.br/ccivil_03/_ato2011-2014/2012/lei/112711.htm.Acesso em: 01 jun. 2019.

BRASIL.Lei $n^{\circ}$ 5.465, de 3 de julho de 1968. Dispõe sôbre o preenchimento de vagas nos estabelecimentos de ensino agrícola.Disponível em:

https://www2.camara.leg.br/legin/fed/lei/1960-1969/lei-5465-3-julho-1968-358564publicacaooriginal-1-pl.html.Acesso em: 20 jun. 2019.

CASTRO, Yeda Pessoa de.Das línguas africanas ao português brasileiro.Patrimônio -Revista Eletrônica do IPHAN,[on line].Disponível em: http://www.labjor.unicamp.br/patrimonio/materia.php?id=214. Acesso em: 22 jun. 2019.

CHASIN, José. A b e r t u r a: AD HOMINEM Rota e Prospectiva de um Projeto Marxista.p.1-42,[s.d].Disponível em:

https://www.marxists.org/portugues/chasin/ano/mes/rota.pdf. Acesso em: 22 jun.2019.

DAFLON, Verônica Toste;CARVALHAES, Flávio;JÚNIOR, João Feres.Sentindo na Pele: Percepções de Discriminação Cotidiana de Pretos e Pardos no Brasil. Dados-Revista de Ciências Sociais, Rio de Janeiro, Vol. 60, n.2,p.292-330,2007.Disponível em: http://www.scielo.br/pdf/dados/v60n2/0011-5258-dados-60-2-0293.pdf.Acesso em:22 jun.2019.

DAVIS, Angela.A Liberdade é uma luta constante.Organização de Frank Barat:tradução de Heci Regina Candiani. São Paulo:Boitempo, 2018.144 p.

DIAS, Gleidson Renato Martins; TAVARES JUNIOR, Paulo Roberto Faber.(orgs.)

Heteroidentificação e Cotas Raciais: dúvidas, metodologias e procedimentos. Canoas, RS: IFRS campus Canoas, 2018.

DOMINGUES,Petrônio. Uma história não contada: negro, racismo e branqueamento em São Paulo no pós-abolição.São Paulo:SENAC, 2004.

DOMINGUES.Petrônio. Um "templo de luz": Frente Negra Brasileira (1931-1937) e a questão da educação. Revista Brasileira de Educação, Rio de Janeiro, v.13, n.39, Set./Dec. 2008.Disponível em: http://www.scielo.br/scielo.php?script=sci_arttext\&pid=S1413-24782008000300008. Acesso em:22 jun.2019.

FRENTE NEGRA BRASILEIRA. Manifesto à Gente Negra Brasileira.1931. [S.I.:s.n.].

INSTITUTO INTERNACIONAL DA LINGUA PORTUGUESA.Das línguas africanas ao português brasileiro.Abril 2013. Disponível em: https://iilp.wordpress.com/2013/04/21/daslinguas-africanas-ao-portugues-brasileiro/. Acesso em: 22 jun. 2019.

KARASCH, Mary C.A vida dos escravos no Rio de Janeiro (1808-1850). Companhia das Letras, 2000.

LANZA, André Luiz; LAMOUNIER, Maria Lucia.A América Latina como destino dos Imigrantes:Brasil e Argentina. Cadernos Prolam/USP 14(26): p. 90-107 [2015].Disponível em: file://C:/Users/CAR/Downloads/102283-Texto\%20do\%20artigo-178583-3-1020151218.pdf. Acesso em:22 jun.2019.

MAESTRI, Mario.A Pedagogia do medo: disciplina, aprendizado e trabalho na escravidão brasileira. In:STEPHANOU, M.; BASTOS, M.H.C.(orgs.).Histórias e Memória da Educação no Brasil. Vol. I - séculos XVI a XVIII. Petrópolis,RJ: Cortez, 2004. p.192-209. 
MATOSSO, Katia M. de Queirós. Ser escravo no Brasil. São Paulo: Ed. Brasiliense, 1982.

MBEMBE,Achille.Necropolítica, biopoder soberania estado de exceção política da morte.Temáticas,2016.Disponível em:https://www.procomum.org/wpcontent/uploads/2019/04/necropolitica.pdf. Acesso em: 22 jun. 2019.

MENEZES, Jaci Maria Ferraz de. Educação e Cor-de-pele na Bahia - o acesso à educação de negros e mestiços, 2007,p.1-12.Disponível em:

http://www.sbhe.org.br/novo/congressos/cbhe2/pdfs/Tema6/0601.pdf. Acesso em: 22 jun.2019

MENEZES. Jaci Maria Ferraz de.As Duas Pedagogias: formas de educação dos escravos; mecanismos de formação de hegemonia e contra-hegemonia.Revista Histedbr On-line. Campinas, n.28, p.145 -163, dez. 2007.Disponível em: https://www.fe.unicamp.br/pffe/publicacao/5029/art10_28.pdf.Acesso em:22 jun.2019.

MIRANDA, Shirley Aparecida de.Procedimento de Heteroidentificação:breve relatório do Registro Acadêmico 2019/2.2019.[S.1.: s.n.].

NUNES, Georgina Helena Lima.Autodeclarações e Comissões: responsabilidade procedimental dos/as gestores/as de ações afirmativas.In:DIAS, Gleidson Renato Martins; TAVARES JUNIOR, Paulo Roberto Faber(Org). Heteroidentificação e Cotas Raciais: dúvidas, metodologias e procedimentos.Canoas,RS:IRFS Campus Canoas, 2018.p.11-30.

ORGANIZAÇÃO DAS NAÇÕES UNIDAS.Declaração e Programa de Ação adotados na III Conferência Mundial de Combate ao Racismo, Discriminação Racial, Xenofobia e Intolerância Correlata.31 de agosto a 8 de setembro de 2001. Disponível em: https://www.oas.org/dil/port/2001\%20Declara\%C3\%A7\%C3\%A3o\%20e\%20Programa\%20d e $\% 20 \mathrm{~A} \% \mathrm{C} 3 \% \mathrm{~A} 7 \% \mathrm{C} 3 \% \mathrm{~A} 3 \mathrm{o} \% 20$ adotado\%20pela\%20Terceira\%20Confer\%C3\%AAncia\%20 Mundial\%20contra\%20o\%20Racismo,\%20Discrimina\%C3\%A7\%C3\%A3o\%20Racial,\%20X enofobia $\% 20 \mathrm{e} \% 20$ Formas $\% 20$ Conexas $\% 20 \mathrm{de} \% 20$ Intoler $\% \mathrm{C} 3 \% \mathrm{~A} 2$ ncia.pdf. Acesso em:22 jun.2019.

RIGUEIRA JR, Itamar.Candidatos às cotas raciais passarão por comissão complementar à autodeclaração. 8 de julho de 2019.Disponível

em:https://ufmg.br/comunicacao/noticias/candidatos-a-vagas-pelas-cotas-raciais-passaraopor-comissao-complementar-a-autodeclaracao.Acesso em:27 jul.2019.

SANTOS, Sales Augusto dos.Historical roots of the "whitening" of Brazil. Translated by Lawrence Hallewell.Latin American Perspectives, Issue 122, vl. 29, n.I,p.62, January 2002, p 62.Disponível em: https://www.jstor.org/stable/3185072?read-

now $=1 \&$ refreqid=excelsior\%3A9036b68ec2c9bd66d21657e9471b260f\&seq=1\#page_scan_ta b_contents. Acesso em:27 jul.2019.

SILVA, Adriana Maria Paulo da.A escola de Pretextato dos Passos e Silva: questões a respeito das práticas de escolarização no mundo escravista.Revista Brasileira de História da Educação, n.4,jul./dez. 2002.Disponível em:

https://www.researchgate.net/publication/277761942_A_escola_de_Pretextato_dos_Passos_e _Silva_questoes_a_respeito_das_praticas_de_escolarizacao_no_mundo_escravista.Acesso em: 03 jul.2020.

SILVA NETO, Serafim da.Introdução ao estudo da língua portuguesa no Brasil. 2.ed. 1963,Rio de Janeiro: Instituto Nacional do Livro.

TELLES, Edward; LIM, Nelson. (1998),"Does it Matter Who Answers the Race Question? Racial Classification and Income Inequality in Brazil”.Demography, v.5, n. 4, p.465- 
Braga; A. F.

474.Disponível em:https://link.springer.com/article/10.2307/3004014. Acesso em: 27 jul.2019.

UNIÃO DE NEGRAS E NEGROS PELA IGUALDADE.Ofício. 11 de outubro de 2017.[s.n.].

UNIVERSIDADE FEDERAL DE MINAS GERAIS.Edital Complementar ao Edital do Processo Seletivo para acesso aos cursos presenciais de graduação da UFMG em 2019 pelos candidatos selecionados por meio do SISU com base no resultado do ENEM.Disponível em: https://www.ufmg.br/sisu/wp-content/uploads/2018/12/Edital-complementar-Sisu-UFMG2019.pdf. Acesso em:22 jun.2019.

UNIVERSIDADE FEDERAL DE MINAS GERAIS.Sistema de Seleção Unificada 2020.Disponível em: https://www.ufmg.br/sisu/wp-content/uploads/2019/12/Edital-SisuUFMG-2020.pdf. Acesso em 19 dez.2019.

UNIVERSIDADE FEDERAL DE OURO PRETO.A UFOP e as politicas de ação afirmativa. Disponível em:https://ufop.br/noticias/reitoria/ufop-e-politicas-de-acao-afirmativa em:22jun.2019. 